\title{
CARACTERIZAÇÃo DE AMOSTRAS PETROQUÍMICAS E DERIVADOS UTILIZANDO CROMATOGRAFIA GASOSA BIDIMENSIONAL ABRANGENTE (GCxGC)
}

\section{Carin von Mühlen, Claudia Alcaraz Zini* e Elina Bastos Caramão}

Instituto de Química, Universidade Federal do Rio Grande do Sul, Av. Bento Gonçalves, 9500, 91501-970

Porto Alegre - RS, Brasil

\section{Philip J. Marriott}

Australian Center for Research on Separation Science, School of Applied Sciences, RMIT University, GPO Box 2476V, Melbourne, Victoria 3001, Australia

Recebido em 6/1/05; aceito em 9/8/05; publicado na web em 6/3/06

\begin{abstract}
CHARACTERIZATION OF PETROCHEMICAL SAMPLES AND THEIR DERIVATIVES BY COMPREHENSIVE TWODIMENSIONAL GAS CHROMATOGRAPHY. The goal of this article is to discuss the application of comprehensive two-dimensional gas chromatography (GCxGC) to petrochemical samples. The use of GCxGC for petroleum and petroleum derivatives characterization, through group type analysis, or BTEX (benzene, toluene, ethylbenzene, xylenes), total aromatic hydrocarbons, polyaromatic hydrocarbons, sulfur-containing, oxygen-containing, and nitrogen-containing compounds is presented. The capability of GCxGC to provide additional specific chemical information regarding petroleum processing steps, such as dehydrogenation of linear alkanes, the Fischer-Tropsch process, hydrogenation and oligomerization is also described. In addition, GCxGC analyses of petrochemical biomarkers and environmental pollutants derived from petrochemicals are reported.
\end{abstract}

Keywords: comprehensive two-dimensional gas chromatography; petroleum, fuel.

\section{INTRODUÇÃO}

A cromatografia gasosa bidimensional abrangente (GCxGC, "Comprehensive Two-Dimensional Gas Chromatography") é caracterizada pela utilização sequencial de duas colunas cromatográficas, uma convencional e a outra curta (do tipo de coluna usada para "fast-GC"), de forma que todo o efluente da primeira coluna ou uma parte representativa do mesmo é conduzido para a segunda através de um modulador. O sistema de modulação entre as duas colunas causa uma compressão da banda cromatográfica que elui da primeira coluna, e esta banda é direcionada para a coluna curta, de forma que a separação na segunda coluna é extremamente rápida. Os períodos de modulação devem ser ajustados a fim de que sejam compatíveis com o tempo de separação na segunda coluna, minimizando o alargamento da banda comprimida. Desta forma, a sensibilidade é significativamente incrementada (relação sinal/ruído aproximadamente 10 vezes maior) ${ }^{1,2}$ e a resolução aumenta de forma expressiva, se comparada à cromatografia gasosa monodimensional (1D-GC, "One-Dimensional Gas Chromatography”). A combinação de duas colunas cromatográficas com mecanismos de separação ortogonais entre si leva a um significativo aumento de seletividade. Tais características tornam esta técnica extremamente útil para análise de amostras complexas, ou amostras que apresentem outras características que limitam sua caracterização por $1 \mathrm{D}-\mathrm{GC}$, como no caso das separações enantioméricas ${ }^{1,2}$. Embora a GCxGC tenha apenas 13 anos, vários moduladores já foram desenvolvidos. Inicialmente, eram utilizadas válvulas ou inserção direta na segunda coluna. Entretanto, a fim de focalizar os analitos em bandas estreitas, tornou-se necessário utilizar gradientes térmicos, seja através de temperaturas elevadas, acelerando-se a eluição do soluto dentro de uma banda estreita (abordagem de

*e-mail: cazini@iq.ufrgs.br varredura térmica - "thermal sweeper"), seja através de sistemas criogênicos, retardando-se a eluição dos analitos e causando um aprisionamento "on-column", ou estreitamento das bandas ${ }^{2}$. O primeiro sistema modulador criogênico foi descrito por Marriott e Kinghorn $^{3}$, e é chamado sistema criogênico longitudinalmente modulado (LMCS, "Longitudinally Modulated Cryogenic System"). Outro sistema modulador deste tipo utiliza dois jatos criogênicos a fim de focalizar os compostos em duas regiões próximas da coluna capilar, para separar os eventos de aprisionamento e remobilização da amostra. Estes dois últimos moduladores descritos são os mais utilizados atualmente. Os princípios da $\mathrm{GCxGC}^{1,2,4-11}$, bem como os moduladores desenvolvidos ${ }^{3,12-18}$, já têm sido largamente discutidos na literatura e não serão o enfoque deste trabalho.

Desde seu surgimento, a GCxGC vem sendo aplicada à caracterização de amostras petroquímicas, por um motivo simples: estas amostras são conhecidas como as mais complexas em Química Analítica. O número de compostos, somente no destilado intermediário, foi estimado acima de um milhão ${ }^{19}$. Por este motivo, é praticamente impossível realizar uma caracterização cromatográfica de todos os compostos de uma amostra de petróleo bruto em uma única separação cromatográfica, fazendo-se, portanto, apenas a identificação dos compostos por classes químicas. As classes tipicamente identificadas incluem os n-alcanos ou parafinas, alcanos ramificados ou iso-parafinas, alcenos ou olefinas, alcenos ramificados ou iso-olefinas, alcanos cíclicos ou naftenos, alcenos cíclicos, aromáticos, aromáticos monocíclicos, aromáticos bicíclicos, aromáticos tricíclicos, compostos contendo heteroátomos, entre outros ${ }^{20}$. Na literatura são apresentadas caracterizações de diversas frações de petróleo e identificação de classes químicas específicas através da GCxGC. Para este tipo de amostras, a estruturação apresentada nos cromatogramas de GCxGC é uma característica fundamental, por permitir a clara separação e identificação dos compostos por classe química. 
Neste trabalho, serão apresentadas as aplicações da GCxGC a amostras petroquímicas, discutindo-se o avanço obtido em termos de incremento de informação analítica, comparativamente à 1DGC. Inicialmente, serão discutidas as aplicações envolvendo a caracterização geral de frações do petróleo e a identificação de classes químicas específicas presentes no petróleo e seus derivados. Posteriormente, são referidas as análises de etapas do processamento do petróleo bruto, os avanços nas análises de biomarcadores e, por fim, aplicações envolvendo poluentes ambientais provenientes de petróleo e seus derivados em amostras de ar, água e solo. Dentre as principais aplicações da GCxGC a amostras petroquímicas estão as análises de gasolina ${ }^{13,14,18,21-30}$, combustíveis para jatos ${ }^{22,31}$, gasóleo leve ${ }^{19,32}$, óleo diesel ${ }^{27,33-38}$, óleo bruto ${ }^{20,39-41}$, solventes hidrocarbonetos não aromáticos ${ }^{20}$, querosene ${ }^{15,20,28,32,42,43}$, óleos de lavagem ${ }^{44}$, biomarcadores ${ }^{40,45-47}$, poluentes ambientais em $\operatorname{ar}^{10,16,26,34,41,45,47-54}$, água e solo e a caracterização de etapas do processamento ${ }^{19,35}$.

\section{CARATERIZAÇÃO GERAL DE AMOSTRAS PETROQUÍMICAS}

As primeiras aplicações da GCxGC a amostras petroquímicas resultaram na caracterização de grupos de compostos através da observação de sua distribuição espacial característica em diagramas de contorno. A Figura 1 ilustra um diagrama de contorno obtido por GCxGC-FID ("Flame Ionization Detector", Detector de Ionização de Chama) para separação de uma amostra de solvente não aromático, onde o eixo das ordenadas representa a separação na primeira dimensão (primeira coluna) e o eixo das abscissas, a separação na segunda dimensão (segunda coluna). A combinação dos cromatogramas da primeira e da segunda dimensão para formação do diagrama de contorno é realizada por software específico. Nesta figura, é possível observar a separação espacial detalhada por classes químicas, em naftenos, parafinas, mono e dinaftenos. Outra característica que pode ser verificada nos diagramas de contorno para este tipo de amostra é o efeito "telhado", no qual o perfil de agrupamento dos picos dentro de uma classe química é repetido para cada número de carbonos, de forma que cada "telha" corresponde a um grupo de compostos pertencentes a uma classe química que apresenta um determinado número de carbonos. Esta distribuição espacial de "telhas" em seqüência no diagrama de contorno auxilia na identificação dos $\operatorname{compostos}^{20}$.

Blomberg e colaboradores ${ }^{19}$ apresentaram um diagrama de contorno da separação de uma amostra de gasóleo leve por GCxGC-FID, utilizando um modulador térmico de varredura, para demonstrar o potencial da técnica. Em apenas $20 \mathrm{~min}$ foi obtida a completa separação por grupo de compostos saturados, mono- e di-aromáticos. Pela análise dos diagramas de contorno obtidos foi possível obter informações detalhadas sobre o ponto de ebulição e distribuição do número de carbonos dos componentes da amostra. Utilizando um outro sistema GCxGC-FID, com um modelo mais novo de modulador térmico, e um injetor PTV ("Programmable Temperature Vaporization", Vaporização com Temperatura Programável), Beens e colaboradore ${ }^{20}$ realizaram a separação de uma amostra da fração leve do petróleo (faixa de destilação $<370{ }^{\circ} \mathrm{C}$ ). Com este sistema, foram separadas as mesmas classes de compostos, além dos tri-aromáticos, apesar da maior complexidade da amostra.

O querosene é formado por uma mistura de hidrocarbonetos alifáticos, naftênicos e aromáticos, com faixa de destilação compreendida entre 190 e $290^{\circ} \mathrm{C}$. Como estes produtos contêm compostos apresentando 10 a 17 carbonos, o número total de componentes provavelmente passa de $100.000^{55}$. A 1 D-GC não é

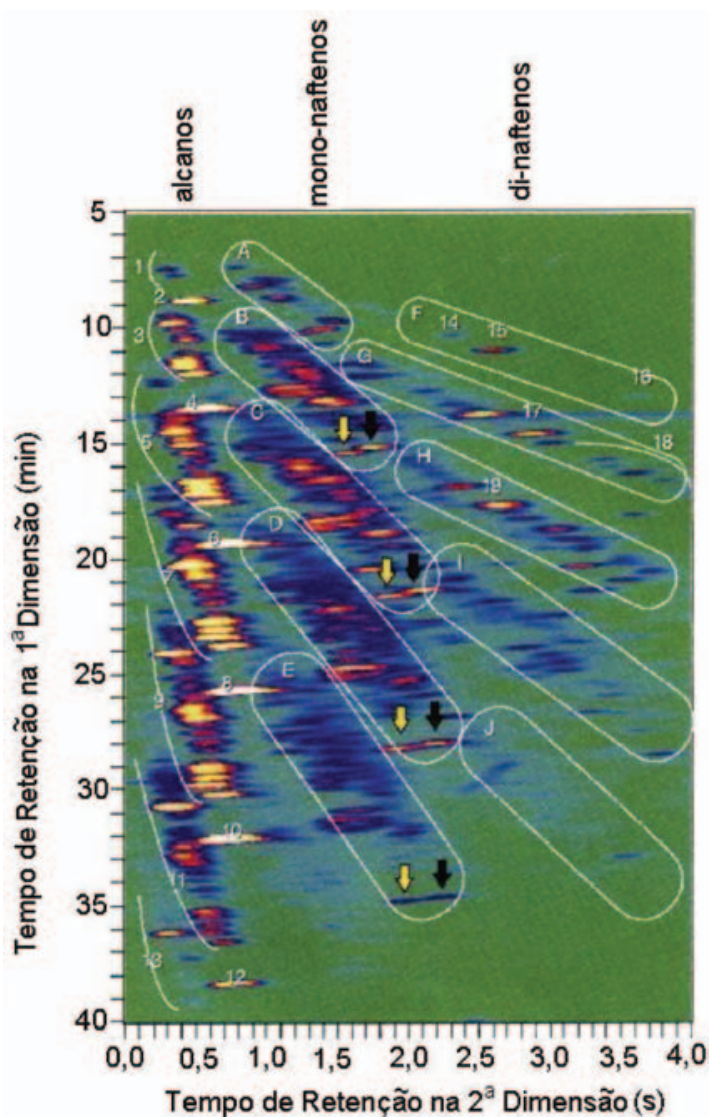

Figura 1. Diagrama de contorno obtido por GCxGC-FID para separação de uma amostra de um solvente não aromático derivado de petróleo. $1 . C_{10}$ ramificados; 2. $C_{10}$ lineares; 3. $C_{11}$ saturados ramificados; 4. $C_{11}$ lineares; 5. $C_{12}$ ramificados; 6. $C_{12}$ lineares; 7. $C_{13}$ ramificados; $8 . C_{13}$ lineares; 9. $C_{14}$ saturados ramificados; 10. $C_{14}$ lineares; $11 . C_{15}$ saturados ramificados; $12 . C_{15}$ lineares; 13. $C_{16}$ saturados ramificados; 14. desconhecidos; 15. trans-decalina; 16. cis-decalina; 17. trans-metil-decalinas; 18. cis-metil-decalinas; 19. $C_{2}-$ decalinas. De A a E, mononaftenos entre $C_{10} e C_{14}$, onde as setas brancas indicam os n-alquilciclopentanos, e as setas pretas os $n$-alquilciclohexanos; de $F$ a J, dinaftenos entre $C_{10}$ e $C_{14}$. Modificado da ref. 20

capaz de separar uma mistura com tantos compostos e técnicas hifenizadas sofisticadas, como HPLC - CG (HPLC, "High Performance Liquid Chromatography", Cromatografia Líquida de Alta Eficiência), não conseguem realizar a separação das frações saturadas de aromáticos mono- e bicíclicos ${ }^{43}$. Em 1993, Venkatramani e colaboradores ${ }^{42}$ realizaram a primeira separação de uma amostra de querosene por GCxGC-FID, obtendo mais de 600 picos e identificando as classes de compostos separadas. Mais tarde, Beens e colaboradore ${ }^{20}$ realizaram a caracterização de querosenes por GCxGC-FID, utilizando o sistema descrito anteriormente. Neste trabalho, ainda não foi possível realizar a completa separação das classes de compostos, apenas a separação em mono-, di-aromáticos, naftenos, n-alcanos e alcanos ramificados. Observou-se também que ocorreu a sobreposição de algumas bandas de alcanos altamente ramificados com alcanos lineares, além de ter-se verificado baixa resolução entre alcanos e iso-alcanos. van Deursen e colaboradores ${ }^{32}$ caracterizaram querosene por um sistema semelhante aos anteriores, mas com detector TOFMS ("Time-Of-Flight Mass Spectrometry”, Espectrometria de Massas por Tempo de Vôo). No cromatograma resultante da Corrente Total de Íons (TIC - "Total Ion Current"), a separação obtida também foi muito seme- 
lhante, contudo, utilizando-se os recursos do Cromatograma de Íons Extraídos (EIC, "Extracted Ion Chromatogram") ou de um software para deconvolução automática dos espectros de massas, foi possível realizar a separação das classes de compostos de acordo com seus respectivos íons característicos. Alguns exemplos de classes separadas foram alcanos, di-naftenos e compostos contendo heteroátomos, como sulfurados e oxigenados. Dentro da categoria dos compostos sulfurados, foram separadas as classes dos dimetil-benzotiofenos e dos n-etil-benzotiofenos. Entretanto, a separação entre alcanos lineares e ramificados não ficou evidente.

Bruckner e colaboradores ${ }^{21}$, em 1998, realizaram uma das primeiras aplicações da GCxGC à análise de gasolina, mas não tiveram por objetivo a separação dos compostos. Amostras de gasolina fortificadas com tolueno, etil-benzeno, m-xileno e propilbenzeno foram utilizadas para demonstrar o uso de análises de segunda ordem dos dados de GCxGC para quantificação de picos sobrepostos, com auxílio de técnicas multivariadas como o Método Generalizado de Aniquilação de Posto (GRAM, "Generalized Rank Annihilation Method"). Neste trabalho, foi utilizado um sistema modulador com válvula diafragma e um GCxGC - FID. Foram também realizados estudos de incerteza relativa do tempo de retenção (definido como o desvio padrão do tempo de retenção de um pico para várias injeções dividido pela largura da base do pico), alcançando-se um desvio padrão estimado em 0,01 , em um total de quatro injeções.

Frysinger e colaboradores ${ }^{24}$ empregaram um sistema GCxGCFID com modulador de rotação térmica na caracterização de amostras de gasolina e outros líquidos inflamáveis, com intuito de identificar estes líquidos em incêndios criminosos. Vários compostos conhecidos como marcadores, os quais fornecem informações sobre o tipo de líquido inflamável e seu fornecedor, puderam ser facilmente identificados nos diagramas de contorno, além de terse obtido a usual identificação das classes químicas presentes. Em amostras de gasolina, foi possível separar e identificar MTBE (Metil-Terc-Butil-Éter), benzeno, tolueno, alquilbenzenos $\mathrm{C}_{2}, \mathrm{C}_{3}$, $\mathrm{C}_{4}$ e $\mathrm{C}_{5}$, naftaleno e $\mathrm{C}_{1}$-naftalenos, em $110 \mathrm{~min}$. Os grupos aromáticos são normalmente designados pelo número de átomos de carbono substituintes, como benzenos com um átomo de carbono substituinte - benzenos $\mathrm{C}_{1}$ (tolueno), com dois átomos de carbono substituintes - benzenos $C_{2}$ (etil-benzenos e xilenos), e assim por diante. Nos resultados obtidos por cromatógrafo gasoso acoplado a espectrômetro de massas (GC/MS, "Gas Chromatograph coupled to Mass Spectrometer") a resolução dos grupos alquilbenzenos $\mathrm{C}_{4}$ e $\mathrm{C}_{5}$ em gasolina foi muito pobre, porém, os mesmos foram bem resolvidos por GCxGC. Também foram realizados estudos qualitativos sobre a perda de compostos voláteis por envelhecimento destes líquidos e análises de resíduos pirolisados de incêndio (carpete), com os quais foi possível identificar os isômeros $\mathrm{C}_{3}$ de alquilbenzenos, característicos de líquidos derivados de petróleo.

Óleos de lavagem à base de hidrocarbonetos líquidos são utilizados em plantas de produção de etileno para minimizar o acúmulo de sujeira no compressor ${ }^{44}$. Quanto maior a quantidade de compostos aromáticos pesados neste tipo de óleo, melhores são suas propriedades para esta aplicação. No trabalho de Sun e colaboradores $^{44}$, foram utilizadas as técnicas GCxGC-FID com modulador criogênico de duplo jato, GC/MS e GC-AED ("Atomic Emission Detector", Detector de Emissão Atômica) para caracterização de dois óleos de lavagem diferentes. Através de uma análise rápida dos diagramas de contorno obtidos, verificou-se que, em um dos óleos, a maioria dos componentes eluiu na faixa de $n-C_{12}$ a n- $C_{16}$, e para o outro óleo, na faixa de
$n-C_{12}$ a n- $C_{20}$. Nos diagramas de contorno obtidos, os compostos foram agrupados em três bandas: apolares, aromáticos de 1 e 2 anéis, e poliaromáticos. Devido à estruturação espacial presente nos diagramas de contorno, foi possível calcular a relação percentual destas bandas de compostos nas amostras. Estas características demonstraram que o segundo óleo apresentava maior quantidade de compostos aromáticos pesados e uma faixa de ponto de ebulição mais ampla, o que o torna mais indicado para esta aplicação, sem necessidade de identificação de cada pico cromatográfico. Também foram realizados estudos de repetibilidade, que resultaram em um desvio padrão $(n=3)$ de 0,17 e 0,15 para os compostos aromáticos e 0,17 para os compostos alifáticos. Os resultados obtidos para as áreas de picos cromatográficos, através do emprego de dois programas distintos de integração, foram consistentes, visto que a diferença relativa entre áreas ficou entre 0,04 e 1,6\%.

\section{CARACTERIZAÇÃO DE CLASSES DE COMPOSTOS ESPECÍFICAS PRESENTES NO PETRÓLEO E DERIVADOS}

\section{Compostos aromáticos}

Os compostos aromáticos pesados não são resolvidos por métodos ASTM baseados em GC que utilizam multi-colunas, sendo normalmente separados por grupos, como aromáticos com 8 carbonos, com 9 carbonos, e assim por diante. O método ASTM que emprega GC/MS é uma alternativa para evitar a complexidade instrumental dos métodos GC multi-colunas, contudo, ele apenas atenua os problemas de co-eluição, sendo menos confiável no que se refere à quantificação. Frysinger e colaboradores $^{25}$ identificaram e quantificaram BTEX (Benzeno, Tolueno, Etilbenzeno, Xilenos) e todos os compostos aromáticos pesados presentes em amostras de gasolina por GCxGCFID, utilizando um modulador térmico. Neste trabalho, o grupo aromáticos $\mathrm{C}_{8}$ inclui os benzenos $\mathrm{C}_{2}$, e o grupo aromáticos $\mathrm{C}_{9}$ abrange vários isômeros estruturais de um e dois anéis aromáticos. Os compostos aromáticos quantificados por $\mathrm{GCxGC}$ foram benzenos $\mathrm{C}_{3}$, benzenos $\mathrm{C}_{4}$, benzenos $\mathrm{C}_{5+}$ (5 ou mais carbonos substituintes), ,naftaleno, naftalenos $\mathrm{C}_{1}$ e naftalenos $\mathrm{C}_{2}$. Os resultados do método desenvolvido foram comparados com os obtidos através de métodos ASTM, apresentando diferenças devidas às formas de cálculo da linha de base e ao estabelecimento de diferentes padrões, visto que os métodos ASTM empregam sistemas multicolunas ou GC/MS, onde grande parte dos picos não estão resolvidos. Um outro composto bem resolvido por este método foi o MTBE (metil-terc-butil éter), um importante aditivo que aumenta a octanagem da gasolina e diminui a emissão de monóxido de carbono. Esta determinação sinalizou a possibilidade de quantificação de éteres e outros compostos oxigenados por este método, o que foi, posteriormente, realizado pelos mesmos pesquisadores (ver item sobre Compostos oxigenados).

Fraga e colaboradores ${ }^{22}$ relataram a rápida análise quantitativa de três isômeros aromáticos (isopropilbenzeno, propilbenzeno e 1,3,5-trimetilbenzeno) em combustível para jato por GCxGC-FID de alta velocidade, sendo a modulação realizada com válvula diafragma, utilizando o método da adição de padrão, um algoritmo de alinhamento objetivo do tempo de retenção e a técnica quimiométrica GRAM. Com o algoritmo de alinhamento foram realizadas correções de desvios causados por variações instrumentais (como oscilação da vazão da fase móvel ou da temperatura) antes da análise quimiométrica dos dados, pois, como a separação na 
segunda dimensão é muito rápida, qualquer variação afeta significativamente o tempo de retenção dos compostos. Esta correção quadruplicou a precisão e exatidão da quantificação GRAM. Assim, quando as matrizes em análise são quimicamente semelhantes, é possível aplicar o procedimento de adição de padrão e análise quimiométrica para a primeira amostra e, posteriormente, empregar a mesma calibração feita na primeira para as demais amostras, diminuindo significativamente variações, tais como, efeitos de matriz e efeitos instrumentais. A separação cromatográfica bidimensional de alta velocidade dos três compostos foi realizada em 2,8 min, sendo cinco vezes mais rápida que o método de referência empregando GC-FID, onde apenas dois dos três isômeros foram resolvidos, e 10 vezes mais rápida que métodos recentes de GCxGC, que resolvem estes três compostos. Johnson e colaboradores $^{31}$ quantificaram o percentual de naftalenos em 14 amostras de combustível de jato, usando um sistema GCxGC-FID e um modulador de válvula diafragma de alta velocidade para amostragem de gás. Neste trabalho, também foi utilizado um modelo quimiométrico de calibração (PLS-Tri, "Trilinear Partial Least Squares", Mínimos Quadrados Parciais Trilineares), e o algoritmo de alinhamento de tempos de retenção baseado na minimização de postos. Os autores comprovaram que a técnica de alinhamento normalmente empregada para regiões específicas do cromatograma pode ser estendida para alinhar todo o cromatograma, visando melhorar o desempenho dos modelos multivariados de calibração construídos. A modelagem proposta foi suficientemente rápida e determinou os naftalenos de forma precisa nas amostras de combustíveis para jato.

\section{Hidrocarbonetos poliaromáticos}

Os hidrocarbonetos poliaromáticos (PAH - "Polycyclic Aromatic Hydrocarbons") são espécies homocíclicas, que possuem apenas carbono e hidrogênio e que apresentam pelo menos dois anéis condensados, sendo produzidos prioritariamente por queima de combustíveis fósseis, sendo dispersados no ar ou depositados nas superfícies terrestre ou aquática ${ }^{56}$. Os PAH abrangem centenas de compostos de elevada toxicidade para os seres humanos, afetando também organismos presentes no solo e plantas. Muitos PAH estão listados como poluentes prioritários pela Agência de Proteção Ambiental dos Estados Unidos da América ("US EPA - U.S. Environmental Protection Agency") $)^{57}$ devido à suspeita de carcinogenicidade e mutagenicidade atribuídas a estes compostos. Elevadas concentrações de PAH são encontradas em regiões de produção ou utilização de destilados pesados de petróleo, carvão ou alcatrão $^{50}$. A caracterização destes compostos em solo, água e ar por GCxGC será discutida, posteriormente, juntamente com os outros compostos presentes nestas matrizes.

A quantificação de PAH em derivados do petróleo é bastante difícil dada a baixa concentração desses compostos e a elevada complexidade das matrizes, o que torna impossível sua caracterização sem uma etapa de "cleanup" adequada. Vários métodos foram propostos para quantificação destes compostos ${ }^{58}$, envolvendo técnicas de GC, HPLC ${ }^{59}$, ou ambas hifenadas ${ }^{60}$, Cromatografia com Fluido Supercrítico (SFC, "Supercritical Fluid Chromatography") ${ }^{61}$, Cromatografia a Gás Solvatante (SGC, "Solvatiog Gas Chromatography") ${ }^{62}$, entre outras, além de técnicas para préfracionamento da amostra. Apesar da técnica mais utilizada ser GC/MS, a quantificação de PAH em amostras complexas ainda não está claramente resolvida, devido à co-eluição de isômeros posicionais, o que acrescenta aos métodos propostos etapas demoradas de "cleanup", que aumentam o tempo de análise e as perdas dos analitos.

As inúmeras vantagens da GCxGC já apresentadas para caracte- rização de amostras complexas frente às outras técnicas levaram Cavagnino e colaboradores ${ }^{63}$ a desenvolverem um método analítico para determinação de PAH em óleo diesel usando um sistema GCxGC-FID com modulador criogênico de duplo jato e um novo sistema de injeção para grandes volumes de amostra, o que aumenta ainda mais a sensibilidade do sistema. Para comprovar a eficiência do sistema proposto, foi utilizada uma mistura certificada de PAH em óleo diesel. Os limites de detecção encontrados para estes compostos situaram-se na faixa de unidades de ppbs, e o desvio padrão relativo da área dos picos, para 5 injeções, na faixa de $1 \%$. A identificação dos compostos da mistura, bem como os resultados quantitativos foram compatíveis com os dados certificados.

\section{Compostos sulfurados}

A dessulfuração de combustíveis tem recebido grande atenção devido à carcinogenicidade de vários compostos sulfurados, além dos danos que estes compostos causam ao meio ambiente ${ }^{40}$. As restrições da legislação de vários países relativamente a compostos que contêm enxofre em gasolina e óleo diesel têm se apresentado progressivamente demandantes. Somado a isto, quantidades cada vez maiores de compostos mais pesados contendo enxofre têm sido encontradas no petróleo, o que resulta em altos níveis de enxofre no combustível gerado ${ }^{27}$. A fim de desenvolver novos catalisadores para remoção de compostos sulfurados dos combustíveis, é necessário conhecer as estruturas moleculares dos mesmos $^{39}$. Entretanto, a caracterização destes compostos é muito trabalhosa e demorada, devido à complexidade dos isômeros presentes. Sendo assim, o desenvolvimento de tecnologias que permitam sua rápida caracterização em matrizes de petróleo e derivados torna-se essencial ${ }^{27}$.

Em 2000, van Deursen e colaboradores ${ }^{32}$ empregaram pela primeira vez a GCxGC na caracterização de compostos sulfurados e oxigenados no petróleo, já utilizando um sistema GCxGC/TOFMS com modulador térmico. Em uma amostra de querosene com alta concentração de compostos contendo enxofre foi possível isolar os benzotiofenos (BT) empregando a corrente total de íons. Selecionando os fragmentos de íons com $\mathrm{m} / \mathrm{z} 161$ e 176, foram separados dimetil-benzotiofenos, n-etil-m-metil-benzotiofenos e dietilbenzotiofenos em três grupos distintos, facilitando a posterior identificação de cada composto.

van Stee e colaboradores ${ }^{39}$ utilizaram GCxGC-AED para amostras de petróleo e produtos do craqueamento catalítico em leito fluidizado (FCC - "Fluidised Catalytic Cracking") e correlacionaram os resultados com aqueles obtidos por $\mathrm{GCxGC/}$ TOFMS. O FCC é utilizado para converter cadeias alquílicas longas $\left(>\mathrm{C}_{12}\right)$ em cadeias mais curtas $\left(<\mathrm{C}_{5}\right)$ produzindo, portanto, combustíveis leves. Nos diagramas de contorno GCxGC-AED foi possível observar a modificação do número de carbonos dos compostos sulfurados através do FCC. Nas amostras de petróleo estão presentes, principalmente, os BT altamente alquilados, dibenzotiofenos (DBT) e benzonaftotiofenos (BNT). Nos produtos de FCC, entretanto, os compostos sulfurados com alto ponto de ebulição não foram encontrados e os compostos sulfurados aromáticos moderadamente alquilados (C1-C6) predominaram. A identificação dos compostos sulfurados desconhecidos exigiu a combinação e correlação dos resultados obtidos por TOFMS e AED. O alinhamento direto dos cromatogramas obtidos por GCxGC-AED e GCxGC/TOFMS não pôde ser realizado, pois o tempo de retenção dos compostos nas duas dimensões é distinto. Enquanto MS está sob vácuo, AED encontra-se próximo à pressão atmosférica, de forma que a pressão no ponto de conexão das duas colunas é diferente, alterando a retenção nas duas dimen- 
sões. Para verificar a correlação entre os dados, foram realizadas modificações na geração gráfica dos diagramas de contorno, alterando-se o tempo de modulação via software e, também, comprimindo e esticando um dos cromatogramas ao longo do eixo da primeira dimensão. Para enfatizar a importância deste alinhamento, basta dizer que um dos compostos foi erroneamente identificado antes deste processo, o que foi corrigido posteriormente. Neste trabalho também foi possível caracterizar o composto fenantro[4,5-bcd]tiofeno, que não é comumente encontrado em frações de petróleo. A combinação das informações obtidas com os dois detectores diminuiu drasticamente o número de possíveis fórmulas moleculares, auxiliando na identificação de compostos desconhecidos.

Wang e colaboradores ${ }^{37}$ quantificaram BT e DBT por grupo de isômeros presentes em amostras de diesel usando GCxGC com Detector por Quimiluminescência de Enxofre (SCD, "Sulfur Chemiluminescence Detector") e modulador térmico de duplo jato. Os diagramas de contorno obtidos por GCxGC foram comparados a cromatogramas gerados em um sistema GC-SCD convencional, nas mesmas condições cromatográficas da primeira dimensão do sistema bidimensional. No cromatograma convencional, os compostos sulfurados ficaram agrupados na região entre 30 e $80 \mathrm{~min}$, formando uma banda não resolvida. Por GCxGC os picos foram resolvidos até a linha de base, com o mesmo tempo de análise (80 min), permitindo sua quantificação.

Hua e colaboradore ${ }^{27}$ realizaram um estudo amplo sobre a separação, identificação e quantificação de compostos sulfurados presentes em óleos diesel provenientes de diferentes unidades de processo, utilizando um sistema semelhante de GCxGC-SCD com modulador térmico de jato simples. Para esta determinação foram testados 5 conjuntos de colunas diferentes. A separação dos diferentes grupos de compostos sulfurados presentes no diesel foi realizada em $135 \mathrm{~min}$, ao passo que, para outros métodos como LC-GC-SCD ${ }^{64}$, são necessários dois ou três dias de análise. Os resultados demonstraram que a distribuição dos compostos contendo enxofre em óleos diesel provenientes de diferentes óleos brutos varia enormemente com a unidade de processamento secundário. Foram analisadas amostras de óleo diesel provenientes de destilação de petróleo, resíduo de FCC (RFCC), "visbreaking" (VB) e craqueamento retardado (DC "delayed-coking"). Foram observadas grandes alterações no perfil de distribuição dos compostos sulfurados para cada tipo de processamento, ao passo que a contribuição das diferentes origens do óleo diesel para diferenciação do perfil cromatográfico dos compostos sulfurados foi muito pequena. Com os resultados inéditos obtidos por GCxGC, foi possível verificar que os DBT são os compostos sulfurados mais difíceis de serem removidos do óleo diesel, de forma que os catalisadores e outros parâmetros de operação dos processos de dessulfuração deveriam ser selecionados levando-se em consideração a concentração dos DBT, ao invés do conteúdo total de enxofre.

$\mathrm{O}$ mesmo grupo de pesquisa realizou um estudo semelhante na separação, identificação e quantificação de compostos sulfurados em petróleo ${ }^{40}$. Utilizando um software comercial, foram detectados 3620 picos, sendo 1722 de tióis/tioéteres, dissulfetos e tiofenos de um anel, 953 de BT, 704 de DBT e 241 de BNT. É impossível realizar uma separação como esta por métodos 1D-GC. O tempo de análise requerido para esta separação foi idêntico ao trabalho anterior $^{27}$. Os pesquisadores também realizaram a quantificação de vários compostos $\mathrm{BT}$ e DBT individualmente, presentes em petróleos de três origens diferentes (Djeno, Zaflro e Oman), obtendo-se recuperações entre 90 e 102\%. Os resultados foram comparados com o método ASTM D-4294, obtendo-se um desvio padrão rela- tivo menor que $4,2 \%$ para o total de sulfurados. O método desenvolvido para GCxGC-SCD parece ser o melhor método existente atualmente para separação e quantificação de impurezas de compostos sulfurados em frações de petróleo.

\section{Compostos oxigenados}

São adicionados à gasolina para diminuir as emissões automotivas, melhorando a qualidade do ar em áreas poluídas. Frysinger e Gaines ${ }^{23}$ continuaram o desenvolvimento do método apresentado anteriormente ${ }^{25}$ para identificação e quantificação de BTEX e compostos aromáticos em amostras de gasolina por GCxGC-FID utilizando um modulador térmico, acrescentando ao mesmo a identificação e quantificação de compostos oxigenados. Entretanto, para o método desenvolvido, não foi possível resolver todos os compostos oxigenados estudados, pois alguns éteres co-eluíram com outros compostos da matriz, mesmo empregando-se três fases estacionárias diferentes na segunda dimensão, ou modificando-se a programação de temperatura, buscando aumentar a retenção na segunda dimensão. Por outro lado, quando os dados resultantes da análise de duas amostras de referência por GCxGC foram comparados com os obtidos pelos métodos ASTM e US EPA, verificouse que foram atingidos maiores valores percentuais de oxigenados através da técnica bidimensional. $\mathrm{O}$ valor verdadeiro de oxigenados presentes nestas amostras não é conhecido, mas muitos destes métodos levam em consideração apenas a quantidade de MTBE, ao passo que o método desenvolvido através de GCxGC-FID identificou e quantificou três compostos oxigenados majoritários, além de álcoois em nível de traços, o que amplia a faixa de compostos oxigenados quantificáveis. Segundo os autores, é possível identificar e quantificar BTEX, compostos aromáticos e oxigenados em gasolina com uma única corrida de apenas $1 \mathrm{~h}$. van Deursen e colaboradores $^{32}$ sinalizaram a possibilidade de analisar compostos oxigenados e sulfurados em querosene, juntamente com os demais compostos, empregando GCxGC/TOFMS, através da seleção de íons característicos das classes químicas de interesse, aumentando a seletividade para estas classes.

\section{Compostos nitrogenados}

Os compostos nitrogenados presentes no óleo diesel são responsáveis por envenenamento de catalisadores, facilitam as reações de oxidação, formando gomas e causando mau cheiro, além de contribuírem para as emissões gasosas, causando poluição atmosférica. Para investigar estes problemas, a utilização de uma técnica adequada para especiação de compostos nitrogenados em óleo diesel é fundamental. Wang e colaboradores ${ }^{38}$ demonstraram a utilização da GCxGC com Detector por Quimiluminescência de Nitrogênio (NCD, "Nitrogen Chemiluminescence Detector") para especiação de compostos nitrogenados em óleo diesel, pois técnicas tradicionais como GC-NCD ou GC/MS não separam adequadamente estes compostos. A Figura 2 ilustra um cromatograma obtido por GC-NCD convencional (A) para uma amostra de óleo diesel, um cromatograma GCxGC-NCD (B), e um diagrama de contorno processado de GCxGC-NCD (C). No diagrama de contorno, o eixo $X$ representa a separação na primeira dimensão (volatilidade) e o eixo $Y$, a separação na segunda dimensão (polaridade). A baixa resolução dos compostos na 1D-GC (A) aumentou drasticamente no cromatograma apresentado para GCxGC (B), mas a identificação dos picos ficou muito prejudicada pela grande quantidade de picos presentes no cromatograma, sem qualquer ordenamento. A conversão deste cromatograma em um diagrama de contorno (C) permite a clara observação dos agrupa- 


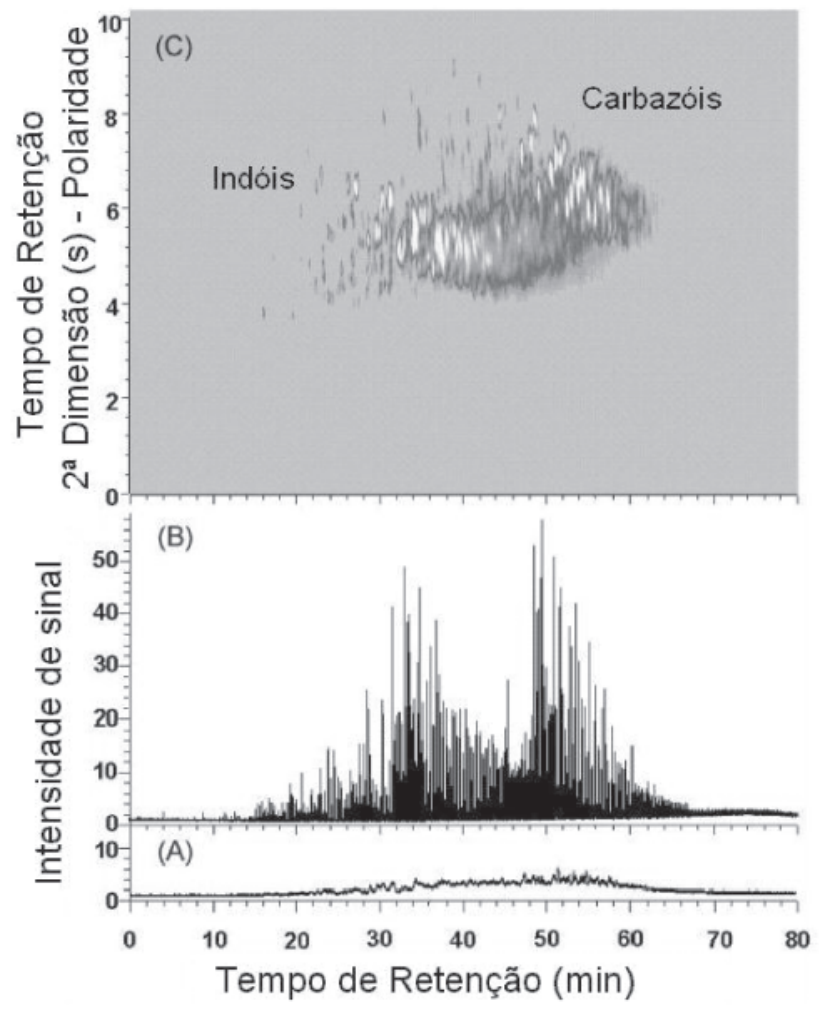

Figura 2. Análise de compostos nitrogenados em uma amostra típica de óleo diesel por (A) cromatograma de GC-NCD tradicional; (B) cromatograma $G C x G C-N C D$; $(C)$ diagrama de contorno processado de GCxGC-NCD. Modificado da ref. 38

mentos por classes químicas, além de facilitar a identificação dos compostos. Não foram realizados estudos quantitativos para todos os compostos, mas a identificação das classes químicas permitiu acompanhar um processo de Hidrodesnitrogenação (HDN, "Hydrodenitrogenation"). Comparando os diagramas de contorno obtidos antes e após a HDN, observa-se que praticamente todos os picos da região que contém compostos nitrogenados desapareceram. Após um outro processo de desnitrogenação, quase toda a classe dos indóis foi removida. Alguns carbazóis e indóis foram identificados e quantificados individualmente.

\section{CARACTERIZAÇÃO DE ETAPAS DO PROCESSAMENTO DO PETRÓLEO}

\section{Desidrogenação de alcanos lineares ${ }^{35}$}

Hidrocarbonetos saturados lineares são muito utilizados em petroquímica devido à sua elevada reatividade. Como exemplo, podem ser utilizados como reagentes de alquilação para produção de alquilbenzenos (surfactantes). Os alquilbenzenos são normalmente obtidos pela desidrogenação de alcanos lineares alcançando-se baixas taxas de conversão (máximo de 20\%). Desta reação também resultam subprodutos, como compostos aromáticos e dialcenos. A quantidade destes subprodutos deve ser limitada, pois os compostos aromáticos são responsáveis pela formação de gomas, e as diolefinas são inibidores catalíticos. Atualmente, não é possível realizar sequer uma caracterização das classes químicas destas frações por 1D-GC, muito menos uma análise detalhada da composição química, devido à co-eluição de algumas frações, como por ex. aromáticos e dialcenos, isoalcanos e alcenos. Nem mesmo através da GC/MS este problema foi resolvido, pois não é possível realizar a deconvolução do espectro de massas em nível de traços. Por GCxGC com um modulador de dois jatos de $\mathrm{CO}_{2}$, foi possível obter facilmente a separação de diferentes classes químicas e realizar uma determinação precisa do peso relativo dos constituintes da mistura de partida e dos produtos, com taxas de conversção de 10 e $20 \%$. Outra informação adicional obtida por GCxGC foi a não detecção de compostos insaturados na mistura de partida, o que sugere que os mesmos são formados durante o processo.

\section{Processo Fischer-Tropsch ${ }^{35}$}

O processo Fischer-Tropsch converte carvão, gás natural e produtos de baixo valor para refino em produtos limpos de alto valor. Por este motivo, esta tecnologia tem ganhado importância desde o conhecimento da limitação das reservas petrolíferas há algumas décadas. Por este processo, os alcanos lineares são os principais produtos formados a partir de hidrogênio e monóxido de carbono. Eles podem ser utilizados como combustíveis, ou na produção de ceras. O subseqüente hidrocraqueamento/hidroisomerização dos produtos de Fischer-Tropsch melhora suas propriedades térmicas a baixas temperaturas, possibilitando sua mistura com diesel. Estes combustíveis são considerados ambientalmente adequados, pois não contêm compostos sulfurados ou aromáticos e apresentam boas propriedades de combustão (com um alto número de cetano). Durante o processo Fischer-Tropsch, outros produtos são formados, como por ex., isoalcanos, alcenos e álcoois. Na separação por 1DGC, a maior parte dos álcoois co-eluem com os isoalcanos, de forma que apenas os álcoois lineares primários são identificados. A GCxGC pode contribuir com um número maior de informações sobre a composição da amostra, pois permitiu a detecção de, em média, 4 isômeros de cada álcool, os quais eluíram com o mesmo tempo de retenção na segunda dimensão. A posição da hidroxila em cada isômero não pôde ser precisamente determinada, porém o acoplamento da GCxGC a um TOFMS poderia solucionar este ponto. Além disso, a GCXGC permitiu a já mencionada separação de cada classe química por número de carbonos, que em 1D-GC não é possível. Em relação à 1D-GC, a GCxGC apresentou um desvio padrão relativo entre as áreas normalizadas dos picos na faixa de 0,1 a $3,3 \%$ para n-alcanos.

\section{Hidrogenação}

Blomberg e colaboradores ${ }^{19}$ utilizaram a GCxGC-FID com modulador de rotação térmica para caracterização exaustiva de um corte da destilação $\left(150-400{ }^{\circ} \mathrm{C}\right)$ de um Ciclo de Craqueamento Catalítico de um Óleo Pesado (HCCCO - "Heavy Catalytic Cracked Cycle Oil") e de seus produtos de hidrogenação. Vários compostos foram identificados nestas amostras, sendo eles saturados, mono-, di-, tri-aromáticos e compostos sulfurados. Nos diagramas de contorno apresentados foi possível perceber o desaparecimento dos compostos sulfurados listados e a conversão das olefinas após a hidrogenação. Cromatogramas semelhantes poderiam ser obtidos por um sistema hifenizado do tipo NPLC-GC ("Normal Phase Liquid Chromatography", Cromatografia Líquida em Fase Normal), mas os autores apresentam o tempo de análise como principal limitante, uma vez que, para cada fração separada da NPLC é necessária uma corrida cromatográfica por 1D-GC. O tempo de análise por GCxGC corresponde ao tempo empregado em uma corrida 1D-GC. Outra vantagem neste caso, já mencionada para outras aplicações, é a rápida visualização das classes químicas dos compostos no diagrama de contorno GCxGC, permitindo a clara diferenciação dos produtos formados. 
Um dos desafios analíticos da indústria petroquímica é encontrar uma solução satisfatória para caracterização de solventes do destilado intermediário. Muitos fabricantes estão comercializando solventes com diferentes faixas de pontos de ebulição (entre 100 e $300{ }^{\circ} \mathrm{C}$ ) para várias aplicações diferentes. Em função da legislação ambiental, estes solventes praticamente não contêm hidrocarbonetos aromáticos. Normalmente, estes produtos são obtidos de uma fração onde os compostos aromáticos foram hidrogenados, resultando nos compostos naftênicos correspondentes. A quantidade e a natureza dos vários compostos naftênicos presentes determinam as propriedades de solvência do solvente não aromático. Logo, a separação e análise destes compostos em uma matriz parafínica é muito importante. Beens e colaboradores $^{20}$ caracterizaram solventes não aromáticos por GCxGC-FID, usando um modulador térmico de varredura. Com este sistema, foi possível separar não apenas os naftenos das parafinas, mas também os mono- e di-naftenos, os quais foram agrupados em diferentes bandas cromatográficas, como ilustrado na Figura 1 e apresentado anteriormente. Entretanto, para o grupo das parafinas, ainda ocorreram algumas sobreposições de picos. O analisador PIONA (Parafinas, Iso-parafinas, Olefinas, Naftenos e Aromáticos), que é comumente empregado para este tipo de análise, não é capaz de separar completamente naftenos e parafinas com número de carbonos maior que onze. Como a distribuição de átomos de carbono em solventes hidrocarbonados está entre 7 e 20, a separação alcançada por GCxGC é um grande avanço em relação ao que se obtinha através do analisador PIONA.

\section{Oligomerização $^{35}$}

A oligomerização de monômeros é uma forma interessante de produzir alcenos ramificados, geralmente utilizados para gasolina, querosene e óleo diesel. Este processo consiste na adição repetida de moléculas de buteno, formando uma mistura de alcenos mais pesados, entre 8 e 20 átomos de carbono. Uma amostra de um processo de oligomerização foi analisada por 1D-GC, ocorrendo a separação de isoalcanos e alcenos. Entretanto, a possível presença de compostos aromáticos não pôde ser analisada. Sendo assim, a amostra foi submetida à GCxGC. Surpreendentemente, foram encontrados alquilbenzenos, cuja presença pode ser oriunda da transferência de hidrogênios entre os alcenos durante o processo de oligomerização, formando isoalcanos com um número menor de carbonos e compostos aromáticos com um número maior de carbonos. Desta forma, a GCxGC foi utilizada para análise qualitativa de compostos que não foram separados por 1D-GC. Estas informações obtidas por GCxGC permitiram um melhor estudo do mecanismo de reação da oligomerização, o que pode propiciar futuras modificações do processo, visando a melhoria do mesmo.

\section{BIOMARCADORES}

São moléculas orgânicas que fazem parte da composição do petróleo, são resistentes a alterações químicas e cuja estrutura molecular carrega uma forte indicação de que tenham sido criados em quantidades significativas por processos biológicos ${ }^{65}$.

A identificação destes biomarcadores no óleo bruto pode levar à caracterização do tipo de ambiente deposicional (lacustre, terrestre ou marinho), do tipo de organismo vivo presente naquele ambiente, da era geológica em que foi formado o petróleo e, também, do estágio de maturação e degradação deste petróleo ${ }^{47,66}$. Em casos de desastres ambientais, a caracterização da origem do petróleo pode fornecer informações para fins judiciais ${ }^{45}$.

As duas moléculas mais abundantes e conhecidas como biomarcadores são pristano (2,6,10,14-tetrametil-pentadecano) e fitano (2,6,10,14-tetrametil-hexadecano). Estes biomarcadores isoprenóides são derivados da degradação da clorofila ou provenientes de bactérias ${ }^{65}$. Outros biomarcadores presentes no petróleo são esteranos e triterpanos. Estes esteranos são derivados da degradação de esteróis, presentes em plantas superiores e algas. Sendo assim, apresentam átomos de carbono quirais presentes nas junções entre a estrutura tetracíclica e a ramificação alquílica da cadeia. Os triterpanos são derivados dos triterpenóides, presentes nas bactérias, e podem ser tri, tetra ou pentacíclicos. Dentre estes, o grupo mais importante geoquimicamente é o dos hopanos pentacíclicos. Existem muitos outros biomarcadores importantes, como por ex. algumas classes de compostos aromáticos alquilados, tiofenos, e outros compostos sulfurados ${ }^{46}$. A caracterização destes biomarcadores em amostras petroquímicas é uma tarefa difícil, devido à variedade de classes químicas presentes, com diferentes características de volatilidade e polaridade, baixas concentrações, além da alta complexidade inerente às amostras. A $1 \mathrm{D}-\mathrm{GC}$ não é capaz de separar os biomarcadores presentes em menores quantidades, mas a identificação destes compostos pode ser feita por GC/ MS utilizando-se o EIC ("Extracted Ion Chromatogram", Cromatograma do Íon Extraído) para isolamento de classes específicas de compostos em função de relações massa/carga $(\mathrm{m} / \mathrm{z})$ características destas classes. Por ex., quando o $\mathrm{m} / \mathrm{z}$, escolhido é 156 , o EIC apresenta isômeros de naftalenos substituídos com dois carbonos. Entretanto, o EIC para uma classe específica pode conter picos de compostos de outros grupamentos químicos, uma vez que moléculas diferentes podem apresentar o mesmo fragmento de massa ${ }^{46}$.

O primeiro trabalho apresentando a aplicação da GCxGC na identificação de fontes de vazamento de óleo foi realizado em 1999, por Gaines e colaboradores ${ }^{45}$. Foram coletadas amostras de emulsão de óleo em água salgada, e de diesel dos tanques existentes próximos ao local do vazamento (duas possíveis fontes geradoras do vazamento). Utilizando um GCxGC-FID com modulador de rotação térmica, foram identificados vários compostos que co-eluem em 1D-GC para o diesel, além de vários biomarcadores, caracterizando-se a fonte geradora qualitativa e quantitativamente. Foram identificados 61 compostos, sendo 23 benzenos com cadeias alquílicas de 2 a 6 carbonos, 8 naftalenos, antraceno, 4 metil-antracenos, 3 bifenilas, 9 cicloalcanos, 11 alcanos lineares $C_{10}$ a $\mathrm{C}_{20}$, pristano e fitano. Comparando-se visualmente os diagramas de contorno obtidos, verificou-se que no diagrama da fonte 2 de diesel aparecia um número consideravelmente menor de picos na região dos aromáticos pesados que no diagrama de contorno obtido da água marinha poluída. Além disso, foram utilizadas quatro regiões dos diagramas de contorno obtidos para a amostra de água do mar e para as duas amostras de fontes de diesel para fins de comparação de similaridade entre os picos. As regiões escolhidas foram a dos naftalenos, antracenos e fenantrenos, dos alcanos lineares e cíclicos, e também foram investigados os compostos que normalmente são utilizados para discriminação entre fontes de óleo - n-heptadecano, n-octadecano, pristano e fitano. Nos quatro grupos, a fonte geradora 1 foi considerada similar à água do mar e a fonte geradora 2 diferente. As conclusões obtidas foram as mesmas da USCG MSL ("U.S. Coast Guard Marine Safety Laboratiories", Laboratórios de Segurança Marinha da Guarda Costeira dos Estados Unidos), que empregou HRGC e GC/MS para caracterização da fonte de óleo diesel.

Frysinger e Gaines ${ }^{46}$ empregaram o mesmo sistema GCxGCFID do trabalho anterior para analisar biomarcadores em óleo bruto e compararam os resultados obtidos com aqueles conseguidos através de GC/MS. A GCxGC foi efetiva na separação, agrupamento e identificação de importantes classes de biomarcadores não identificados no trabalho anterior, tais como BT, fluorenos, esteranos, hopanos e esteranos triaromáticos, somando 73 compostos identificados. Porém, em algumas regiões do cromatograma, a GCxGC apresentou resolução inferior à alcançada por 1D-GC com 
EIC. Segundo os autores, esta perda de resolução seria devida ao tipo de modulação empregado (modulador de rotação térmica), o que pôde ser confirmado quando comparamos a largura da banda do pulso de injeção gerada por este tipo de modulador $(16-20 \mathrm{~ms})$ com as larguras obtidas com outros moduladores mais recentes, como os moduladores criogênicos com jatos (menor que $10 \mathrm{~ms}$ ), que são significativamente menores, aumentando a resolução ${ }^{1}$. Mesmo com estes resultados, os autores consideram a utilização da GCxGC vantajosa frente à GC/MS EIC, principalmente com relação à imagem gerada, uma vez que no diagrama de contorno é possível visualizar todas as bandas dos biomarcadores simultaneamente, inclusive as daqueles compostos presentes em baixas concentrações ou desconhecidos.

Em outro trabalho do mesmo grupo de pesquisa ${ }^{47}$, utilizando o mesmo sistema GCxGC-FID, foi realizada a caracterização da degradação do petróleo em sedimentos provenientes de um derramamento de petróleo ocorrido em West Falmouth, em 1969. O acompanhamento da degradação do petróleo neste sedimento vem sendo realizado desde 1970 , porém por GC-FID. Burns e Teal ${ }^{67}$ realizaram o estudo desta degradação por GC-FID até 1979, no qual relataram a degradação total de alcanos ramificados nos primeiros 7 anos após o derramamento. Este resultado foi obtido pela medida das relações n-C17/pristano, n-C18/fitano e, quando os nalcanos não eram mais detectáveis, foi utilizada a relação fitano/ linha base, obtida através da comparação do sinal do FID para fitano em relação à linha base da UCM ("Unresolved Complex Mixture", Mistura Complexa Não Resolvida), no mesmo tempo de retenção. Para o óleo original, a relação fitano/linha base encontrada foi 1,5; para o sedimento após 6 anos de degradação foi 0,2 e, em 1976 quando não conseguiram mais resolver o fitano da linha base, a relação foi 0,0 . Por GCxGC, Reddy e colaboradores ${ }^{47}$ resolveram o fitano em uma amostra deste sedimento coletada em 2000, encontrando para a relação fitano/linha base o valor 0,3 . Este resultado foi uma evidência de que a degradação microbiológica do fitano não avançou muito após duas décadas, o oposto do que foi concluído anteriormente, utilizando-se apenas GC-FID. Também foram identificados, por classes químicas, os biomarcadores discutidos nos dois trabalhos anteriores, além de ter sido alcançada a resolução de centenas de picos na região que anteriormente apresentava uma UCM. Com os resultados encontrados, foi possível caracterizar, por ex., um mecanismo de perda preferencial de compostos mais solúveis em água, como os alquilnaftalenos, seja pela lixiviação por água ou pela degradação microbiológica, além de se concluir que apenas os n-alcanos foram completamente degradados. Desta forma, a caracterização do estágio de degradação tornou-se mais completa devido ao maior número de informações obtidas, surgindo daí novos parâmetros para este tipo de estudo.

\section{PETRÓlEO NO AMBIENTE: SOLO E SEDIMENTOS, ÁGUA, AR E PARTICULADOS ATMOSFÉRICOS}

A determinação de poluentes no ambiente é um grande desafio para os químicos analíticos pois, além da complexidade das matrizes, os poluentes estão presentes na faixa de ppb até ppt. Além disso, as matrizes ambientais apresentam uma grande quantidade de compostos, os quais podem co-eluir com os analitos. No que diz respeito à análise de poluentes derivados de petróleo em solos, sedimentos, água, ar e particulados, a GCxGC apresenta grandes avanços, os quais serão apresentados na sequência deste texto.

\section{Solo e sedimentos}

A degradação do petróleo em sedimentos de um desastre ambiental foi estudada por Reddy e colaboradores ${ }^{47}$, como apresentado no item sobre biomarcadores. Frysinger e colaboradores ${ }^{54}$ analisaram amostras de sedimentos contaminados com petróleo por GCxGC estudando a faixa UCM de hidrocarbonetos. Usaram um detector FID e um modulador de rotação térmica e os resultados foram comparados com aqueles obtidos por GC/MS. As amostras de sedimento foram extraídas por ASE ("Acelerated Solvent Extraction", Extração Acelerada com Solvente) e o extrato obtido foi fracionado em colunas de sílica gel e sílica gel modificada com nitrato de prata, obtendo-se quatro frações: alcanos e cicloalcanos, aromáticos com um anel, com dois anéis, e com três ou mais anéis aromáticos. Apesar do processo de fracionamento não ter sido muito eficiente - visto que as frações obtidas continham outros compostos além dos esperados - a saturação dos diagramas de contorno foi muito menor que no caso das amostras não fracionadas, o que facilitou a identificação dos picos e aumentou a sensibilidade. Empregando a GCxGC, obteve-se o percentual em massa de cada classe presente na UCM, além da detecção de traços de n-alcanos, o que seria bastante difícil através outros métodos analíticos. Este grau de separação permite um cálculo preciso da relação n- $\mathrm{C}_{17} /$ pristano para amostras onde estes picos são normalmente perdidos na banda da UCM, como discutido anteriormente. Comparando-se os resultados obtidos por GC/MS e por GCxGC para alguns grupos específicos de compostos, como os fenantrenos e DBT, observa-se que o GC/MS foi mais seletivo, pois estas classes apresentam valores de volatilidade e polaridade semelhantes, o que dificulta a separação por classes na GCxGC, mas torna fácil a separação através da escolha de íons característicos de seus espectros de massas. Se fosse utilizado um sistema GCxGC/TOFMS, este contraponto não seria limitante do processo de separação. Anteriormente, o mesmo grupo já havia realizado uma varredura de extratos de sedimento marinho por uma metodologia bastante semelhante ${ }^{24}$, identificando também PAH e PCB ("Polychlorinated Byphenils", Bifenilas Policloradas) nas amostras, porém com um enfoque apenas qualitativo.

No que diz respeito a quantificar classes específicas de contaminantes derivados de petróleo em amostras de solo, os trabalhos de Hyötyläinen e colaboradores ${ }^{16}$ e Ong e colaboradores ${ }^{50}$ podem ser destacados. O primeiro grupo de pesquisadores ${ }^{16}$ quantificou PAH e PCB em uma amostra certificada de solo, a fim de comprovar a eficiência do modulador criogênico de duplo jato de dióxido de carbono desenvolvido por eles. Neste sistema foi utilizado o forno de um GC e, após o modulador, foi colocada uma peça "Y" para conectar duas colunas distintas para a segunda dimensão, sendo uma das colunas conectada a um FID e a outra, a um ECD ("Electron Capture Detector", Detector de Captura de Elétrons). Desta forma, PCB e PAH foram quantificados ao mesmo tempo, utilizando-se um detector seletivo e outro universal. A solução padrão de PAH utilizada continha 17 compostos, e a de PCB, 15 compostos. As amostras de solo foram extraídas por Soxhlet, e para "cleanup" foi empregado um processo modificado da literatura para PCB. Os PAH e PCB foram separados em apenas uma corrida, obtendo-se resultados quantitativos compatíveis com valores certificados, sem necessidade de eliminação de hidrocarbonetos em mais uma etapa de "cleanup". Os índices de recuperação para os $\mathrm{PAH}$ situaram-se em média ao redor $87 \%$, porém os compostos mais pesados não puderam ser quantificados. Como justificativa para isto, os autores apresentaram a baixa recuperação dos PAH mais pesados no sistema de "cleanup".

Ong e colaboradores ${ }^{50}$ compararam as técnicas de GCxGC-FID, GC-FID e GC/MS para determinação quantitativa de PAH em amostras de solo. No sistema GCxGC foi utilizado um modulador LMCS ("Longitudinally Modulated Cryogenic System", Sistema 
Criogênico Longitudinalmente Modulado). Foram estudados três métodos de extração e "cleanup" para amostras de solo, usando ASE e coluna de sílica, concomitantemente ou em duas etapas. Para esta comparação, foram empregados um sistema GC/MS e um GCxGCFID, não sendo observadas diferenças significativas entre os resultados obtidos pelos três métodos. Para identificação e quantificação dos compostos nos extratos foi utilizado o método do padrão externo e uma mistura padrão contendo $24 \mathrm{PAH}$. Nos diagramas de contorno, os PAH ficaram agrupados em quatro zonas: bicíclicos, tricíclicos com dois anéis aromáticos, tricíclicos com três anéis aromáticos e hexacíclicos. Todos os compostos foram identificados e quantificados por GCxGC nos extratos de solo, com exceção de dois pares de PAH. Os pares benzo(b)fluoranteno e benzo(k)fluoranteno, indeno(cd)pireno e dibenzo(a,c)antraceno não foram separados nas condições cromatográficas empregadas. Em trabalho semelhante realizado por Hyötyläinen e colaboradores ${ }^{16}$ o primeiro par também não foi separado, e o dibenzo(a,c)antraceno não estava presente na mistura, mas sim o dibenzo(a,h)antraceno que não coeluiu com o indeno(cd)pireno. Por 1D-GC a co-eluição de PAH é muito mais significativa, sendo necessário o uso de MS para identificação dos compostos. Ao compararmos as três técnicas, GC-FID, GCxGC-FID e GC/MS, observa-se que a GCxGC apresentou melhores resultados relativamente à separação e quantificação, para o mesmo tempo de análise. Entretanto, especialmente para os compostos de maior massa molecular, a recuperação foi mais baixa que aquela obtida por GC/MS. Tanto neste trabalho de pesquisa, como no trabalho de Hyötyläinen e colaboradores ${ }^{16}$ previamente discutido, as recuperações obtidas para compostos aromáticos pesados foram baixas, quando a técnica analítica instrumental empregada foi GCxGC. Contudo, enquanto os pesquisadores finlandeses ${ }^{16}$ atribuíram esta baixa recuperação a uma excessiva retenção dos analitos no adsorvente usado no processo de "cleanup", o outro grupo de pesquisadore $\mathrm{s}^{50}$ associou a baixa recuperação ao sistema cromatográfico, especialmente na região onde ocorre a transferência dos analitos entre as duas colunas. Segundo Ong e colaboradores $^{50}$, a GCxGC-FID demonstrou ser uma técnica alternativa robusta, que apresenta melhor precisão que a 1D-GC. Foram apresentadas algumas limitações quanto ao "software" utilizado para integração dos picos, mas os resultados indicaram que a associação de ASE e GCxGC é uma ferramenta de grande potencial para varredura de poluentes em amostras ambientais.

\section{Água}

Gaines e colaboradores ${ }^{26}$ aliaram a SPME à GCxGC para análise quantitativa de compostos oxigenados (MTBE e etil-butiléter EBE) e aromáticos (BTEX) em nível de traços em amostras de água. À uma solução padrão contendo estes compostos foram adicionados os alcanos 2,3-dimetilbutano e 2-metilpentano, que normalmente co-eluem com o MTBE em 1D-GC. Como a polaridade destes compostos é diferente da polaridade do MTBE, eles foram separados na segunda dimensão, não co-eluindo com MTBE por GCxGC. A otimização da SPME foi realizada utilizando dois tipos de fibra. $\mathrm{O}$ desvio padrão relativo na quantificação destes compostos ficou abaixo de $10,2 \%$, com limites de detecção abaixo de 0,63 $\mathrm{mL} \mathrm{L}^{-1}$.

Beens e colaboradores ${ }^{51}$ utilizaram um modulador criogênico por eles desenvolvido e um modulador de rotação térmica na separação de uma mistura de 80 poluentes encontrados em águas superficiais e compararam os resultados obtidos. A mistura de poluentes foi composta por aromáticos, alcanos e aromáticos clorados, aldeídos, nitrilas, piridinas, anilinas, álcoois, quinolinas, ftalatos, além de vários pesticidas e herbicidas. A identifi- cação de cada composto foi confirmada por GC/MS. Os resultados obtidos com ambos os moduladores foram muito semelhantes, sendo que todos os compostos foram separados. Estes resultados preliminares demonstraram o potencial da GCxGC na caracterização de compostos de classes químicas muito diferentes.

\section{Ar e particulados atmosféricos}

$\mathrm{Xu}$ e colaboradores ${ }^{48}$ desenvolveram um sistema muito interessante para monitoramento in situ de VOC ("Volatile Organic Compounds", Compostos Orgânicos Voláteis) na atmosfera de Creta, envolvendo um equipamento GCxGC-FID com modulador criogênico de duplo jato. A coleta e a pré-concentração "on-line" dos analitos de interesse foram realizadas utilizando-se "traps" refrigerados e filtros de carvão ativo. $\mathrm{O}$ equipamento funcionava continuamente por ciclos de coleta, injeção, separação cromatográfica e resfriamento, sendo calibrado a cada 5 dias, aproximadamente, utilizando-se uma mistura gasosa padrão contendo 74 hidrocarbonetos em nitrogênio. As informações sobre as variações na concentração dos compostos ao longo do dia e da noite foram obtidas a cada $2 \mathrm{~h}$, entre 2 e 21 de agosto de 2001, sendo os alcanos detectados na faixa de pptv a sub ppbv. Foram monitorados os alcanos $\mathrm{C}_{8}$ à $\mathrm{C}_{11}$, tolueno, etilbenzeno, xilenos, 6 benzenos $\mathrm{C}_{3}$, 2 benzenos $\mathrm{C}_{4}$, indano, acetofenona e aldeído benzeno acético. Com os dados obtidos foi possível estabelecer relações com fontes antropogênicas geradoras dos poluentes, investigar reações químicas e fotoquímicas de degradação, efeitos de diluição, etc. O elevado poder de separação da GCxGC tornou possível o monitoramento simultâneo de vários VOC, o que era praticamente impossível sem esta ferramenta, dadas as demoradas etapas de separação e pré-concentração dos analitos exigidas para uma separação 1D-GC eficiente. Vários cartuchos contendo Tenax TA, Carbopack B e Carboxen 1000 foram utilizados para coletar amostras de ar por 1 ou 2 horas, visado a identificação dos compostos. A análise destes cartuchos foi realizada no mesmo sistema de dessorção térmica, com um equipamento GCxGC nas mesmas condições da análise in situ, porém com um detector TOFMS ${ }^{49}$. Cerca de 650 picos com relação sinal/ruído significativa (>100) foram tentativamente identificados por comparação com espectros de massas de bibliotecas comerciais, apesar de que outros picos cromatográficos, presentes em quantidade semelhante, não foram identificados. Dentre os compostos tentativamente identificados, 235 tiveram sua identidade confirmada por índices de retenção. Cento e cinqüenta destes compostos foram encontrados na faixa $\mathrm{C}_{7}-\mathrm{C}_{14}$ dos diagramas de contorno obtidos nas medidas in situ por GCxGC-FID. Para quantificação destes compostos foi utilizado o método do padrão externo e a integração do volume dos picos cromatográficos. A sensibilidade do sistema GCxGC foi de 20 a 60 vezes superior à do $1 \mathrm{D}-\mathrm{GC}$, com valores de precisão e exatidão comparáveis aos obtidos por 1D-GC.

Kallio e colaboradores ${ }^{52}$ identificaram e quantificaram PAH e PAH oxigenados (oxi-PAH) em particulados atmosféricos de Helsinki, por GCxGG-FID e GCxGC/MS. Em ambos os sistemas foi utilizado um modulador criogênico semi-rotatório desenvolvido no laboratório do próprio grupo de pesquisa. Neste trabalho, as amostras foram coletadas em filtros de fibra de vidro e foram utilizados métodos de fracionamento e "cleanup" por ultra-som e extração em fase sólida (SPE - "Solid Phase Extraction"), separando-se os compostos polares dos apolares. Este fracionamento aumentou a detectabilidade para os compostos de interesse. Também neste trabalho, a quantificação dos compostos foi feita pelos métodos de adição de padrão e pela integração de volume dos picos. Os 
autores apresentaram a necessidade de confirmação da identidade dos compostos por MS, pois mesmo utilizando a técnica de coinjeção, houve erro na identificação de um determinado composto, como apresentado anteriormente por van Stee e colaboradores ${ }^{39}$. Mais uma vez foi discutida a diferença entre os tempos de retenção para os dois detectores, o que impede a comparação direta dos diagramas de contorno. van Stee e colaboradores ${ }^{39}$ desenvolveram um método para a correta sobreposição dos diagramas de contorno obtidos com os detectores AED e TOFMS, que também poderia ser adotado para os diagramas de contorno gerados com os detectores FID e MS.

Para caracterizar Compostos Orgânicos Semivoláteis (SVOC, "Semi-Volatile Organic Compounds") em material particulado fino com diâmetro inferior a $2,5 \mu \mathrm{m}$, coletado do ar atmosférico de Augusburgo na Alemanha, foi utilizado um GC/TOFMS com Dessorção Térmica Direta (DTD, "Direct Thermal Dessorption") e um GCxGC/TOFMS com um modulador de quatro jatos de nitrogênio ${ }^{53}$. Para retenção dos compostos, durante um dia de amostragem, foram usados filtros de fibra de quartzo, que foram posteriormente recortados e inseridos no sistema DTD para dessorção e inserção na coluna cromatográfica. A amostragem foi realizada diariamente, desde 2002 e continua em andamento até 2005. Na 1DGC não foi possível resolver a maior parte dos picos, sendo que $70 \%$ em massa dos SVOC era composta por uma mistura complexa não resolvida (UCM), e apenas $15 \%$ destes compostos foram quantificados. Dentre os compostos identificados por 1D-GC foram destacados n-alcanos, ácidos carboxílicos e alquil nitrilas de cadeia longa, ésteres, terpenos, esteranos, hopanos, aromáticos substituídos, PAH, oxi-PAH e aromáticos heterocíclicos. Pelo sistema bidimensional foram detectados mais de 15.000 picos. Os autores propuseram um procedimento de classificação dos compostos detectados, de forma que foi possível agrupá-los por classes estruturalmente relacionadas. Dentre as classes identificadas estavam os alcanos, alcenos, cicloalcanos, ésteres e ácidos carboxílicos de cadeia longa, aldeídos, cetonas, além dos aromáticos, identificados também por 1D-GC. O agrupamento por classes foi realizado através da utilização de rotinas de pesquisa com regras definidas pelos autores, para identificação dos grupos de compostos assemelhados, facilitando os trabalhos de rotina. Neste trabalho foi apresentada uma forma interessante de representar o diagrama de contorno, através do chamado diagrama de bolhas, onde a posição da bolha é dada pelos tempos de retenção do pico na primeira e na segunda dimensão, e área da bolha corresponde à área do pico. A Figura 3a apresenta um diagrama de contorno obtido por um sistema GCxGC/TOFMS de uma amostra de aerosol. O diagrama de bolhas resultante de uma parte selecionada da Figura 3a está apresentado na Figura 3c, juntamente com a ampliação da região selecionada do diagrama de contorno que o originou (Figura 3b). Com o desenvolvimento futuro da abordagem empregada neste estudo, poder-se-á utilizá-la em investigações ambientais e epidemiológicos.

\section{CONCLUSÕES}

Apesar de ser uma técnica relativamente recente, a GCxGC já foi aplicada a várias matrizes de petróleo ou dele derivadas, resultando na obtenção de uma grande quantidade de novas informações sobre a composição destas amostras .

Uma das principais vantagens da GCxGC na área petroquímica é a organização estrutural dos diagramas de contorno, a qual facilita a observação das classes químicas presentes e auxilia na identificação de cada composto químico. A alta resolução e sensibilidade alcançadas também se encontram entre as grandes vantagens desta técnica, possibilitando a identificação de centenas de com-
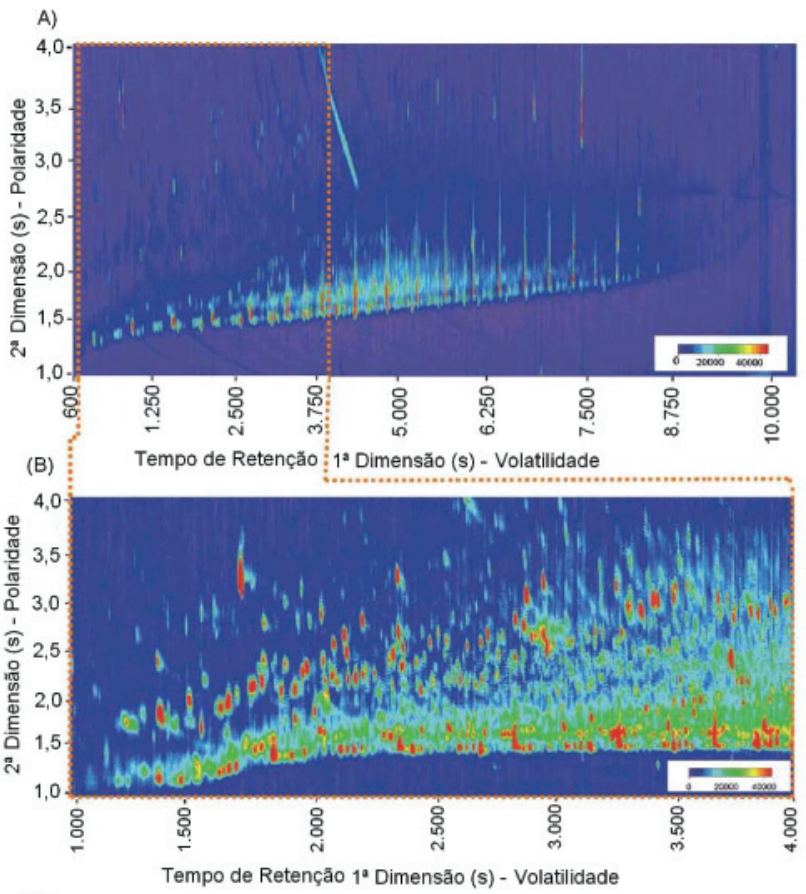

(C)

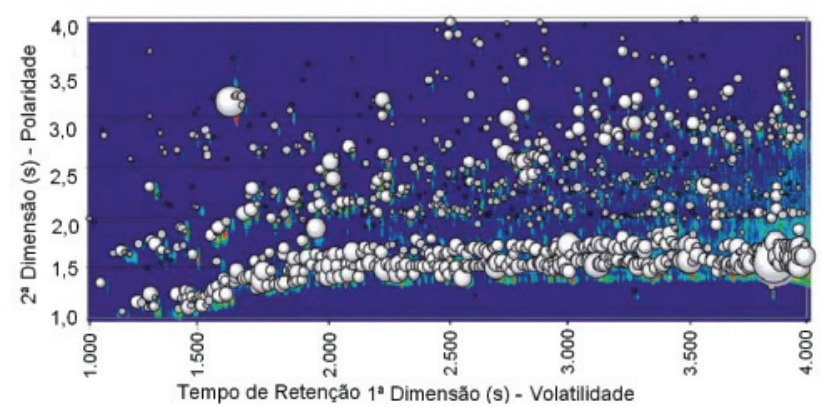

Figura 3. (A) Diagrama de contorno de uma amostra de aerosol; (B) Diagrama de contorno parcial, mostrando apenas uma região selecionada para a análise dos dados; (C) Diagrama de contorno parcial apresentado no item (B), representado como diagrama de bolhas. Modificado da ref. 53

postos que não haviam sido caracterizados anteriormente pela $1 \mathrm{D}$ GC, entre outras técnicas, como no caso das chamadas misturas complexas não resolvidas (UCM). A perspectiva de diminuição de etapas de "clean up", associada ao uso de detector de massas (TOFMS), fornece informações mais precisas sobre a identidade de compostos presentes em amostras complexas que as obtidas em sistemas GC/MS, onde ocorre a co-eluição de vários compostos. A aplicação vantajosa de GCxGC/TOFMS na análise de poluentes de origem petroquímica na área ambiental é um exemplo especialmente relevante.

Estas características permitiram um acompanhamento mais detalhado e eficiente de etapas do processamento do petróleo, o que tornou possível a aquisição de novas informações sobre subprodutos obtidos e mecanismos de reação, possibilitando a melhoria dos processos e do monitoramento dos mesmos.

As aplicações da GCxGC não estão completamente estabelecidas na forma de métodos analíticos definitivos para a maioria das amostras petroquímicas, entretanto, em algumas áreas, como na análise de SVOC em material particulado fino e no monitoramento in situ de VOC, as metodologias analíticas já são utilizadas em trabalhos de rotina, obtendo-se uma grande quantidade de informações confiáveis impossíveis de serem obtidas sem o emprego da GCxGC. 
Tendo como base as vantagens apresentadas pela GCxGC na área petroquímica, pode-se esperar um grande acréscimo de novas informações, redução do tempo de preparo de amostras e custos mais competitivos em um futuro próximo. Com o amadurecimento da GCxGC, especialmente em relação à instrumentação e software, outras aplicações na área petroquímica deverão surgir, facilitando o desenvolvimento e a utilização de métodos analíticos confiáveis e conseqüente geração de informação analítica inédita.

\section{REFERÊNCIAS}

1. Dallüge, J.; Beens, J.; Brinkman, U. A. Th.; J. Chromatogr., A 2003, 1000, 69

2. Marriott, P. J.; Shellie, R.; TrAC, Trends Anal. Chem. 2002, 21, 573.

3. Marriott, P. J.; Kinghorn, R. M.; Anal. Chem. 1997, 69, 2582.

4. Beens, J.; Brinkman, U. A. Th.; Anal. Bioanal. Chem. 2004, 378, 1939.

5. Bertsch, W.; J. High Resol. Chromatogr. 1999, 22, 647.

6. Gorecki, T.; Harynuk, J.; Panic, J.; J. Sep. Sci. 2004, 27, 359.

7. Hinshaw, J. V.; LCGC Eur. 2004, 17, 2.

8. Marriott, P. J.; Morrison, P. D.; Shellie, R.; Dunn, M. S.; Sari, E.; Ryan, D.; LCGC Eur. 2003, 16, 23.

9. Ong, R. C. Y.; Marriott, P. J.; J. Chromatogr. Sci. 2002, 40, 276.

10. Reichenbach, S. E.; Ni, M.; Kottapalli, V.; Visvanathan, A.; Chemom. Intell. Lab. Syst. 2004, 71, 107.

11. Shellie, R.; Marriott, P. J.; Flavour Frag. J. 2003, 18, 179.

12. Beens, J.; Adahchour, M.; Vreuls, R. J. J.; van Altena, K.; Brinkman, U. A. Th.; J. Chromatogr., A 2001, 919, 127.

13. Hamilton, J. F.; Lewis, A.C.; Bartle, K. D.; J. Sep. Sci. 2003, 26, 578.

14. Harynuk, J.; Górecki, T.; J. Chromatogr., A 2003, 1019, 53.

15. Kinghorn, R.M.; Marriott, P.J.; J. High Resol. Chromatogr. 1998, 21, 620.

16. Hyötyläinen, T.; Kallio, M.; Hartonen, K.; Jussila, M.; Palonen, S.; Riekkola, M. L.; Anal. Chem. 2002, 74, 4441.

17. Kritenson, E. M.; Korytár, P.; Danielsson, C.; Kallio, M.; Brandt, M.; Mäkelä, J.; Vreuls, R. J. J.; Beens, J.; Brinkman, U. A. Th.; J. Chromatogr., A 2003, 1019, 65 .

18. Phillips, J. B.; Gaines, R. B.; Blomberg, J.; Wielen, F. W. M.; Dimandja, J. M.; Green, J.; Granger, J.; Patterson, D.; Racovalis, L.; de Geus, H. J.; Boer, J.; Haglund, P.; Lipsky, J.; Sinha, V.; Ledford Jr, E. B.; J. High Resol. Chromatogr. 1999, 22, 3.

19. Blomberg, J.; Schoenmakers, P. J.; Beens, J.; Tijssen, R.; J. High Resol. Chromatogr. 1997, 20, 539.

20. Beens, J.; Blomberg, J.; Schoenmakers, P. J.; J. High Resol. Chromatogr. 2000, 23, 182

21. Bruckner, C. A.; Prazen, B. J.; Synovec, R. E.; Anal. Chem. 1998, 70, 2796

22. Fraga, C. G.; Prazen, B. J.; Synovec, R. E.; Anal. Chem. 2000, 72, 4154.

23. Frysinger, G. S.; Gaines, R. B.; J. High Resol. Chromatogr. 2000, 23, 197.

24. Frysinger, G. S.; Gaines, R. B.; J. Forensic Sci. 2002, 47, 471.

25. Frysinger, G. S.; Gaines, R. B.; Ledford Jr, E.B.; J. High Resol. Chromatogr. 1999, 22, 195.

26. Gaines, R. B.; Ledford Jr, E. B.; Stuart, J. D.; J. Microcol. Sep. 1998, 10, 597.

27. Hua, R.; Lin, H.; Liu, J.; Zheng, J; Wei, H.; Wang, J.; Lu, X.; Kong, H.; $\mathrm{Xu}, \mathrm{G}$; J. Chromatogr., A 2003, 1019, 101.

28. Hua, R.; Ruan, C. H.; Wang, J. H.; Lu, X.; Liu, J.; Xiao, K.; Kong, H. X.; Xu, G. W.; Acta Chim. Sinica 2002, 60, 2185.

29. Prazen, B. J.; Bruckner, C. A.; Synovec, R. E.; J. Microcol. Sep. 1999, 11, 97.

30. Pursch, M.; Eckerle, P.; Biel, J.; Streck, R.; Cortes, H.; Sun, K.; Winniford, B.; J. Chromatogr., A 2003, 1019, 43.
31. Johnson, K. J.; Prazen, B. J.; Young, D. C.; Synovec, R. E.; J. Sep. Sci. 2004, 27, 410.

32. van Deursen, M.; Beens, J.; Reijenga, J.; Lipman, P.; Cramers, C.; Blomberg, J.; J. High Resol. Chromatogr. 2000, 23, 507.

33. Frysinger, G. S.; Gaines, R. B.; J. High Resol. Chromatogr. 1999, 22, 251.

34. Frysinger, G. S.; Gaines, R. B.; Environ. Forensics 2002, 3, 27.

35. Vendeuvre, C.; Bertoncini, F; Duval, L.; Duplan, J. L.; Thiébaut, D.; Hennion, M. C.; J. Chromatogr., A 2004, 1056, 155.

36. Vendeuvre, C.; Ruiz-Guerrero, M.; Bertoncini, F.; Thiébaut, M.; Hennion, M. C.; Resumo do $2^{\text {nd }}$ International Conference on Comprehensive TwoDimensional Gas Chromatography, Atlanta, USA, 2004.

37. Wang, F. C. Y.; Robbins, W. K.; Di Sanzo, F. P.; McElroy, F. C.; J. Chromatogr. Sci. 2003, 41, 519.

38. Wang, F. C. Y.; Robbins, W. K.; Greaney, M. A.; J. Sep. Sci. 2004, 27, 468.

39. van Stee, L. L. P.; Beens, J.; Vreuls, R. J. J.; Brinkman, U. A. Th.; J. Chromatogr., A 2003, 1019, 89.

40. Hua, R.; Wang, J.; Kong, H.; Liu, J.; Lu, X.; Xu, G.; J. Sep. Sci. 2004, 27, 691

41. Marriott, P. J.; Haglund, P.; Ong, R. C. Y.; Clin. Chim. Acta 2003, 328, 1.

42. Venkatramani, C. J.; Phillips, J. B.; J. Microcol. Sep. 1993, 5, 511.

43. Beens, J.; Tijssen, R.; J. Microcol. Sep. 1995, 7, 345.

44. Sun, K.; Winniford, W.; Griffith, J.; Colura, K.; Green, S.; Pursch, M.; Luong, J.; J. Chromatogr. Sci. 2003, 41, 506.

45. Gaines, R. B.; Frysinger, G. S.; Environ. Sci. Technol. 1999, 33, 2106.

46. Frysinger, G. S.; Gaines, R. B.; J. Sep. Sci. 2001, 24, 87.

47. Reddy, C. M.; Eglinton, T. I.; Hounshell, A.; White, H. K.; Xu, L.; Gaines, R. B.; Frysinger, G. S.; Environ. Sci. Technol. 2002, 36, 4754

48. Xu, X. B.; Williams, J.; Plass-Dulmer, C.; Berresheim, H.; Salisbury, G.; Lange, L.; Lelieveld, J.; Atmos. Chem. Phys. 2003, 3, 1461.

49. Xu, X. B.; van Stee, L. L. P.; Williams, J.; Beens, J.; Adahchour, M.; Vreuls, R. J. J.; Brinkman, U. A. Th.; Lelieveld, J.; Atmos. Chem. Phys. 2003, 3, 665.

50. Ong, R. C. Y.; Lundstedt, S.; Haglund, P.; Marriott, P. J.; J. Chromatogr., A 2003, 1019, 221.

51. Beens, J.; Dallüge, J.; Adahchour, M.; Vreuls, R. J. J.; Brinkman, U. A. Th.; J. Microcol. Sep. 2001, 13, 134

52. Kallio, M.; Hyötyläinen, T.; Lehtonen, M.; Jussila, M.; Hartonen, K.; Shimmo, M.; Riekkola, M.L.; J. Chromatogr., A 2003, 1019, 251.

53. Welthagen, W.; Schnelle-Kreis, J.; Zimmermann, R.; J. Chromatogr., A 2003, 1019, 233.

54. Frysinger, G. S.; Gaines, R. B.; Xu, L.; Reddy, C. M.; Environ. Sci. Technol. 2003, 37, 1653.

55. Beens, J.; Tese de Doutorado, University of Amsterdam, Holanda, 1998.

56. Wilcke, W.; J. Plant Nutr. Soil Sci. 2000, 163, 229.

57. http://www.epa.gov, acessada em Dezembro 2004.

58. V-Dinh, T.; Chemical Analysis of Polycyclic Aromatic Compounds, John Wiley: New York, 1989.

59. Lee, M. L.; Novotny, M. V.; Bartle, K. D.; Analytical chemistry of polycyclic aromatic compounds, Academic Press: New York, 1981.

60. Davies, I. L.; Bartle, K. D.; Williams, P. T.; Andrews, G. E.; Anal. Chem. 1988, 60, 204

61. Sie, S. T.; Rijnders, G. W.; Anal. Chim. Acta 1967, 38, 31.

62. Silva, J. C. R.; Tese de Doutorado, Universidade de São Paulo, Brasil, 2002.

63. Cavagnino, D.; Magni, P.; Zilioli, G.; Trestianu, S.; J. Chromatogr., A 2003, 1019,211

64. Beens, J.; Tijssen, R.; J. High Resol. Chromatogr. 1997, 20, 131.

65. Eglinton, G.; Calvin, M.; Sci. Am. 1967, 216, 32

66. Bechtel, A.; Sachsenhofer, R. F.; Kolcon, I.; Gratzer, R.; Otto, A.; Puttmann, W.; Int. J. Coal Geol. 2002, 51, 31.

67. Burns, K. A.; Teal, J.; Estuar. Coast. Mar. Sci. 1979, 8, 349. 